\title{
Consequences of NMDA receptor deficiency can be rescued in the adult brain
}

\author{
Catharine A. Mielnik $\mathbb{1}^{1} \cdot$ Mary A. Binko ${ }^{2,8} \cdot$ Yuxiao Chen ${ }^{1,3} \cdot$ Adam J. Funk $^{4} \cdot$ Emily M. Johansson $^{5}$. \\ Katheron Intson $\left(^{1}\right)^{1}$ Nirun Sivananthan $\left(^{1}\right)^{1} \cdot$ Rehnuma Islam ${ }^{2} \cdot$ Marija Milenkovic ${ }^{1} \cdot$ Wendy Horsfall $^{1} \cdot$ Ruth A. Ross $^{1}$. \\ Laurent Groc $^{5}$ - Ali Salahpour ${ }^{1} \cdot$ Robert E. McCullumsmith $^{4}$ - Shreejoy Tripathy ${ }^{3}$ - Evelyn K. Lambe $\mathbb{D}^{2,6,7}$. \\ Amy J. Ramsey $\mathbb{( D D}^{1,2}$
}

Received: 10 September 2019 / Revised: 11 July 2020 / Accepted: 29 July 2020 / Published online: 17 August 2020

(c) The Author(s) 2020. This article is published with open access

\begin{abstract}
$\mathrm{N}$-methyl-D-aspartate receptors (NMDARs) are required to shape activity-dependent connections in the developing and adult brain. Impaired NMDAR signalling through genetic or environmental insults causes a constellation of neurodevelopmental disorders that manifest as intellectual disability, epilepsy, autism, or schizophrenia. It is not clear whether the developmental impacts of NMDAR dysfunction can be overcome by interventions in adulthood. This question is paramount for neurodevelopmental disorders arising from mutations that occur in the GRIN genes, which encode NMDAR subunits, and the broader set of mutations that disrupt NMDAR function. We developed a mouse model where a congenital loss-of-function allele of Grinl can be restored to wild type by gene editing with Cre recombinase. Rescue of NMDARs in adult mice yields surprisingly robust improvements in cognitive functions, including those that are refractory to treatment with current medications. These results suggest that neurodevelopmental disorders arising from NMDAR deficiency can be effectively treated in adults.
\end{abstract}

Supplementary information The online version of this article (https:// doi.org/10.1038/s41380-020-00859-4) contains supplementary material, which is available to authorised users.

Amy J. Ramsey

a.ramsey@utoronto.ca

1 Department of Pharmacology \& Toxicology, University of Toronto, Toronto, ON M5S 1A8, Canada

2 Department of Physiology, University of Toronto, Toronto, ON M5S 1A8, Canada

3 Krembil Centre for Neuroinformatics, Centre for Addiction and Mental Health, Department of Psychiatry, University of Toronto, Toronto, ON M5T 1L8, Canada

4 Department of Neurosciences, University of Toledo, Toledo, $\mathrm{OH}$ 43614, USA

5 Interdisciplinary Institute for NeuroScience (IINS) CNRS, Université Bordeaux Segalen, 33000 Bordeaux, France

6 Department of OBGYN, University of Toronto, Toronto, ON M5G 1E2, Canada

7 Department of Psychiatry, University of Toronto, Toronto, ON M5T 1L8, Canada

8 Present address: University of Pittsburgh School of Medicine, Pittsburgh, PA 15213, USA

\section{Introduction}

Greater than $1 \%$ of children are born with a neurodevelopmental disorder [1], including diagnoses of autism spectrum disorder and pervasive developmental delay [2]. Until recently, most children with global developmental delay were not given a more specific diagnosis that could predict treatment or long-term prognosis. Whole-exome sequencing has revolutionised diagnostic assessment and has identified hundreds of genes that can cause intellectual disability and developmental delay through transmitted and de novo variants [3].

Through whole-exome sequencing, a new syndrome called GRIN disorder has been identified that is caused by mutations in one of the seven GRIN genes that encode subunits for N-methyl-D-aspartate-type glutamate receptors (NMDARs). Deleterious missense and nonsense variants in GRIN1, GRIN2A-D, and GRIN3A-B cause encephalopathies that are sometimes first diagnosed as intellectual disability, global developmental delay, epilepsy, autism, and/or schizophrenia [4]. The variants are often de novo heterozygous mutations that act as dominant negatives to reduce NMDAR function, although some variants lead to a gain-of function 
by altered channel gating properties [4]. Regardless of the nature of the mutation, patients with these deleterious variants have a similar syndrome of intellectual disability, and additional symptoms such as epilepsy, autism, cortical visual impairment, and movement disorders [4].

The identification of pathogenic variants in a GRIN gene allows for target-directed pharmacological treatments where approved drugs are available, but gene editing may ultimately be the most effective method to treat neurodevelopmental disorders. The timing of intervention remains a question for the future application of gene editing towards neurodevelopmental disorders. It has been assumed that intervention should occur as early in development as is medically feasible, that waiting risks irremediable damage, and that adults with these conditions are beyond the reach of medical treatment to improve cognitive function. However, these assumptions have not been stringently tested. Currently, there are many adults with these disorders that might also benefit from gene therapy, and it is unknown whether the developmental consequences of disease-causing variants can be reversed in adulthood.

The ability to reverse developmental insults is likely to depend on the nature of the insult. For example, while adult rescue of Rett syndrome gene Mecp2 in mice reversed several phenotypes [5], adult rescue of Shank3 in mice showed a more selective improvement to social behaviours [6]. Thus, it is conceivable that developmental insults to the NMDAR system cannot be overcome with adult intervention, considering the central role of this receptor. Indeed, NMDARs are required for the proper connectivity of developing sensory circuits in the thalamus and cortex [79], for the establishment of both inhibitory [10] and excitatory [11] synapses, and for the patterning of neuron dendritic arborizations [12].

Since there is strong evidence that NMDARs participate in many aspects of neurodevelopment, we asked whether developmental consequences of NMDAR deficiency could be reversed in adult mice. Specifically, we asked whether adult intervention could improve cognitive functions, since intellectual disability is a core symptom of patients with GRIN disorders. GRINI encodes the essential subunit GluN1 that is present in all NMDARs, and null mutations of GRIN1 are lethal in humans [13] and in mice [7, 14]. Considering the well-established role of these receptors in development and synapse refinement, it would be predicted that NMDAR deficiencies caused by GRIN1 mutations, in particular, would be refractory to adult intervention.

To address whether developmental insults to the NMDAR system can be overcome with adult intervention, we developed a mouse model with a congenital global lossof-function allele of Grinl, that could be globally genetically restored, temporally, by gene editing with Cre recombinase. We found that Grinl expression was restored in adulthood, and molecular analysis, cellular function and cognitive functions were quantified as outputs to measure the ability to reverse intellectual disability. Strikingly, we discovered that plasticity at the cellular, synaptic, and behavioural level was evident in the cortex. Furthermore, this rescue of cognitive ability was reproduced in a separate adult cohort and was maintained over a longer recovery time. This study suggests that plasticity of cognitive circuits extends well into adulthood, and that there is an inherent ability to upregulate NMDAR activity and to normalise cognitive outputs.

\section{Results}

\section{Generation of mice with a reversible Grin1 deficiency}

To directly answer whether the developmental consequences of NMDAR deficiency could be rescued in adults, we generated mice with a reversible hypomorphic mutation in Grinl, the essential subunit of all NMDARs. Our previous studies, with a similar mouse line, showed that a $90 \%$ knockdown of functional NMDARs is achieved through the targeted insertion of a neo cassette in an intron of the Grinl gene [15]. In the new mouse line, we added loxP sites flanking the neo cassette to allow for inducible excision of the mutation, so that Cre recombinase could restore the locus to wild type in a conditional manner (Fig. 1a, b).

We intercrossed these mice with Rosa26-CreERT2 mice that ubiquitously express a tamoxifen-inducible Cre recombinase. We first identified the tamoxifen regimen that comprehensively induced Cre activity throughout the brain using a Cre-reporter line (Rosa26-dTomato: Supplementary Fig. 1). We then administered tamoxifen to all genotypes of mice at either postnatal day (PD) 21,42 , or 70 and measured biochemical and behavioural endpoints at either PD98 or PD105 (2-week treatment, multiple-week recovery). Figures 1-4 present data from the PD70 intervention group, allowed to age to PD98. Four genotypes of mice were studied: Grinl ${ }^{+/+}$(WT), Grinl ${ }^{+/+}:$CreTg (WTCre), Grinl $1^{\text {flneo/flneo }}\left(\operatorname{Grin} l^{K D}\right)$, and Grinl $1^{\text {flneo/flneo: }}$ CreTg $\left(\right.$ Grinl $\left.1^{\text {RESCUE }}\right)$. We determined that WT and WTCre mice had similar behavioural phenotypes in all of the subsequent studies (Supplementary Fig. 2), and thus experimental results for WT, Grinl ${ }^{K D}$ and Grin1 ${ }^{R E S C U E}$ mice were compared. Studies were performed with both male and female mice of equal number and powered to study the effect of sex.

We determined the extent of molecular recovery of Grin1 mRNA and GluN1 protein by fluorescence in situ hybridisation and immunofluoresence (Fig. 1c), and the 


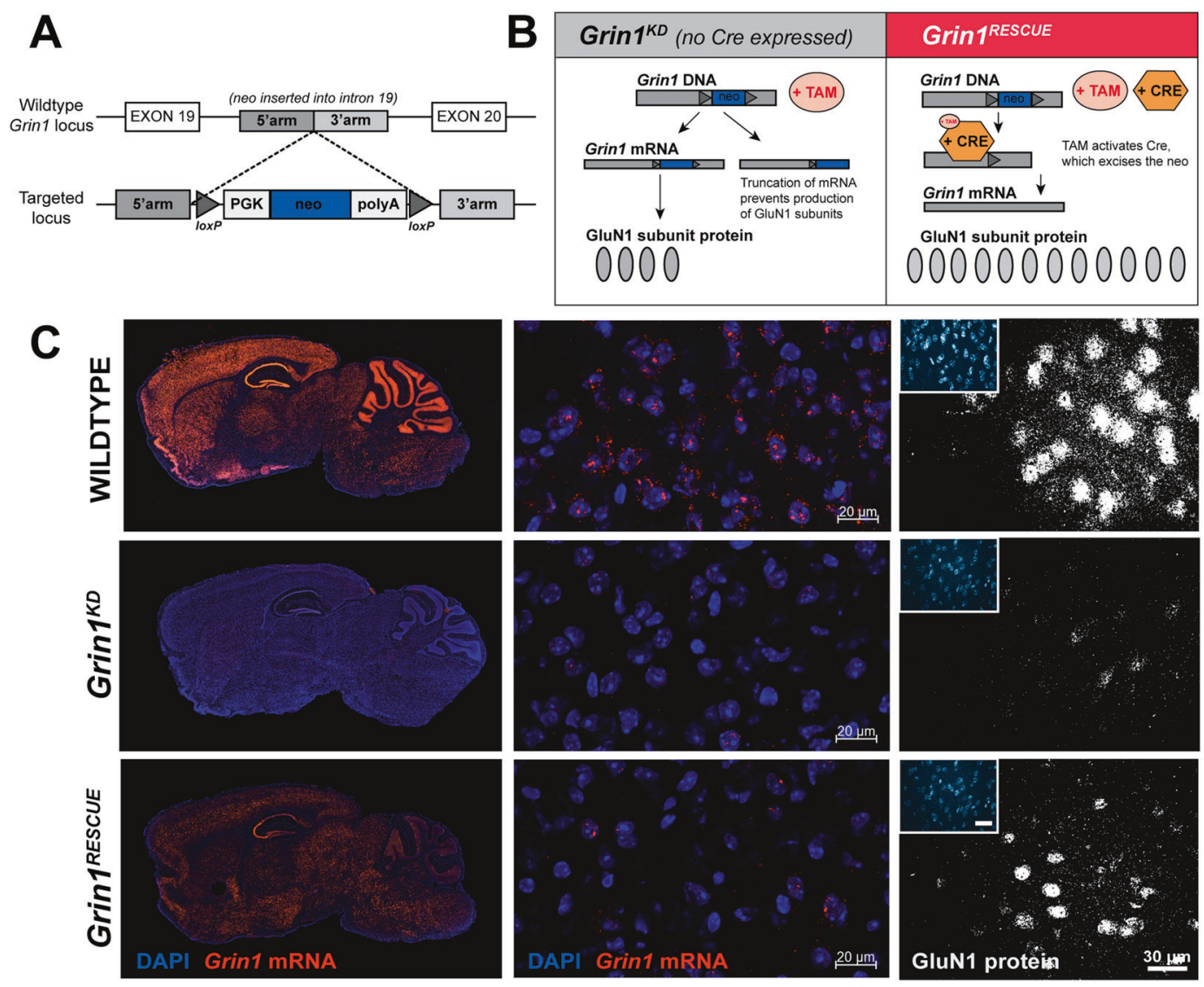

Fig. 1 Generation and molecular characterisation of the Grin1 inducible-rescue mouse line. a Targeting construct schematic and recombination events at the Grinl locus in the generation of the Grinl $1^{\text {fneolffineo }}$ mouse model. PGK, PGK promotor; neo, neomycin selection cassette; polyA, polyadenylation sequence. b Schematic of expected molecular events at the Grin1 locus. c Visualisation of Grin1 mRNA in mouse sagittal sections $(20 \mu \mathrm{m})$ via fluorescent in situ hybridisation using Grin1 probes (left: whole brain; middle: $20 \times$ micrograph of prefrontal cortex). At right, sagittal sections $(20 \mu \mathrm{m})$ of prefrontal cortex visualising GluN1 protein expression via fluorescent immunohistochemistry with a rabbit anti-GluN1 antibody (in-house, 1:200; secondary anti-rabbit Alexa 568) in WT, Grin $1^{K D}$, and Grin1 ${ }^{\text {RESCUE }}$ mice.

Vglutl + cortical neurons (Fig. 2a) but mRNA increases were less consistent in Gadl+ neurons of adjacent sections (Fig. 2b).

Since Cre recombination efficiency is affected by chromatin structure [17], we next queried a cell-type specific ATAC-seq database to determine whether the Grinl locus was more accessible in glutamatergic than GABAergic neurons of the mouse cortex [18]. Chromatin structure of the Grinl locus is indeed more accessible in glutamatergic neurons than in GABAergic neurons (Fig. 2d). Thus, we propose that the more consistent recovery of Grinl mRNA in glutamatergic neurons of the cortex reflects the more available chromatin structure at Grinl in these cells.

\section{NMDAR currents and synaptic GluN1 protein are restored in MPFC neurons}

The extent of functional NMDAR recovery in the cortex was determined through whole cell electrophysiological Grinl ${ }^{R E S C U E}$ mice, Grinl mRNA was generally increased in 
Fig. 2 Grin1 gene expression levels and chromatin accessibility of the adult mouse somatosensory cortex. Grin1 mRNA expression in $V g l u t+(\mathbf{a})$ and $\mathrm{Gadl}+(\mathbf{b})$ cells in the adult mouse somatosensory cortex (1.53 $\mathrm{mm}$ lateral from midline). Grinl (orange), Vglutl (green) and Gadl (yellow) mRNA was visualised in mouse sagittal sections $(20 \mu \mathrm{m})$ with

fluorescent in situ hybridisation in WT, Grin1 ${ }^{K D}$, and Grin1 $1^{\text {RESCUE }}$ mice. Solid white arrows indicate cells with Grinl expression, red arrows indicate cells without Grin1 expression. c Grin1 gene expression levels and d Grin1 chromatin accessibility in wild-type adult mouse visual cortex

glutamatergic (Vglut1+) and GABAergic $(G a d 1+)$ cells. Data are from publicly-accessible single-cell transcriptomics data [16] and pooled cell typespecific ATAC-seq data [18] provided by the Allen Institute for Brain Science.

Transcriptomic data are quantified as counts per million reads sequenced (CPM) and are based on exonic reads only.

ATAC-seq data are quantified as counts per million nucleotides in locus. To aid visualisation, only cells up to the 95th percentile of Grin1 expression or coverage are shown. Data shown as box and whisker plots, 5-95 percentile, Wilcoxon rank-sum test between GLU and GABA.
A
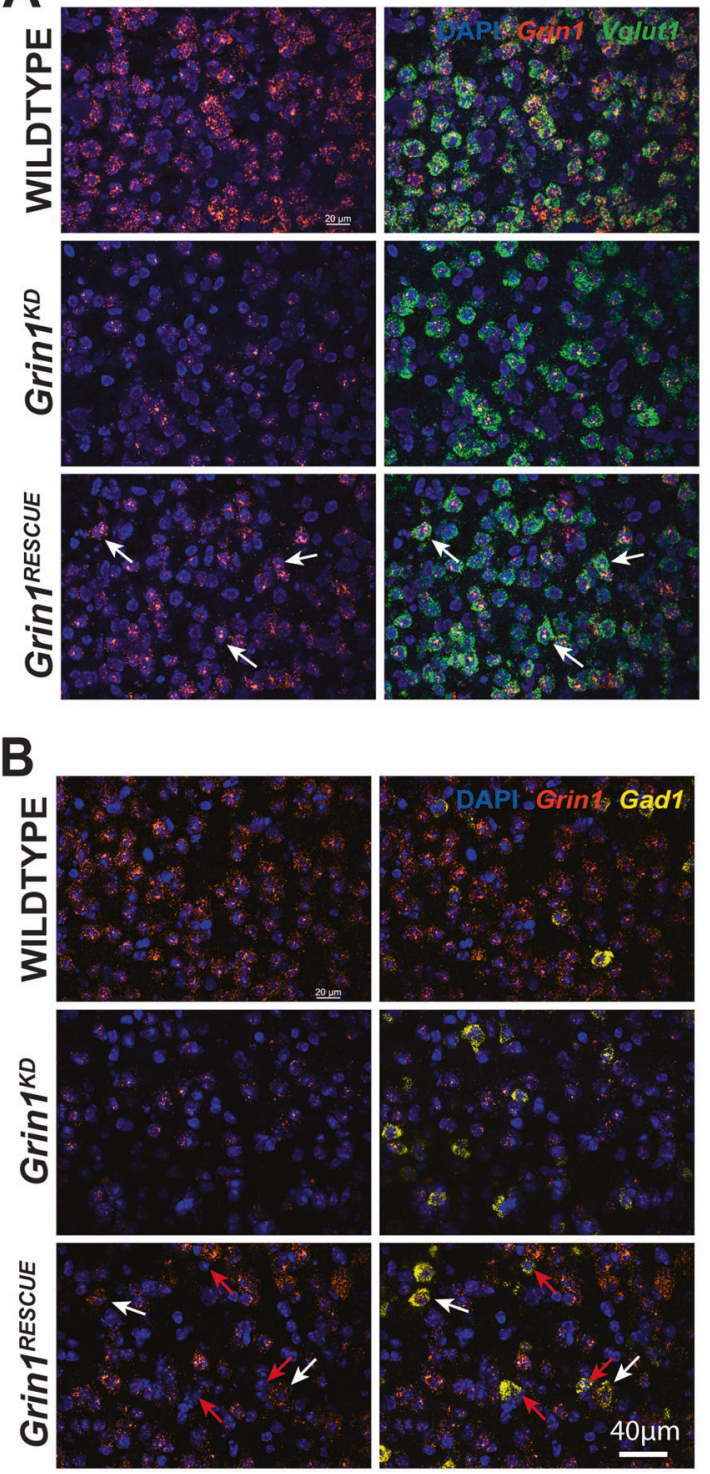
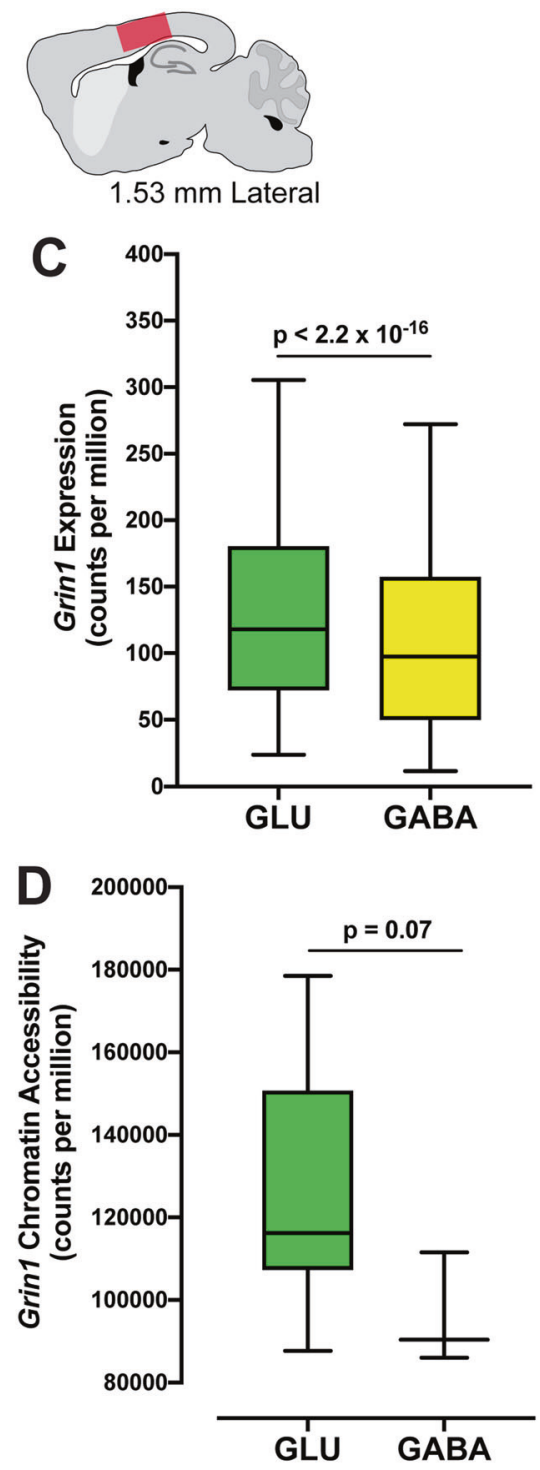

recordings from brain slices. Physiological recordings from layer $\mathrm{V}$ pyramidal neurons of medial PFC (mPFC) were performed (Fig. 3a). Bath applied NMDA elicited an inward current in wild-type cells. This current was greatly attenuated in Grinl ${ }^{K D}$ mice; however, in Grin $1^{R E S C U E}$ mice, NMDA-elicited current was restored to wild-type levels (Fig. 3b, c). The differences in functional NMDARs occurred in the presence of largely similar intrinsic membrane properties (Supplementary Table I). However, capacitance was significantly larger in prefrontal neurons of Grinl ${ }^{\text {RESCUE }}$ compared to WT mice (Fig. 3d). Accordingly, we analyzed the current density of the NMDA-elicited currents (Fig. 3e; effect of genotype, $F_{2,95}=3.6, p=0.03$ ) and found that Grin1 ${ }^{R E S C U E}$ mice also had greatly increased current density compared to Grin $1^{K D}$ mice.
Non-NMDA glutamate receptors in layer $\mathrm{V}$ neurons were examined by measuring spontaneous excitatory postsynaptic potentials (sEPSCs) under conditions that preclude NMDAR opening (holding potential of $-75 \mathrm{mV}$ with $2 \mathrm{mM}$ $\mathrm{Mg}^{2+}$ ). There was no difference in the amplitude of sEPSCs in slices from the three genotypes of mice, indicating similar levels of functioning for AMPA and kainate receptors (Supplementary Fig. 4). There was, however, an increase in the frequency of sEPSCs in Grinl $1^{K D}$ neurons. The elevated synaptic input of Grin ${ }^{K D}$ layer V neurons was normalised in Grinl ${ }^{R E S C U E}$ mice, suggesting an improvement in E/I balance (Supplementary Fig. 4).

As further demonstration of synaptic NMDAR recovery in the PFC, the levels of GluN1 protein were determined by immunoprecipitation with anti-PSD-95 antibody and mass 
Prefrontal Cortex (Layer V Pyramidal Neurons)
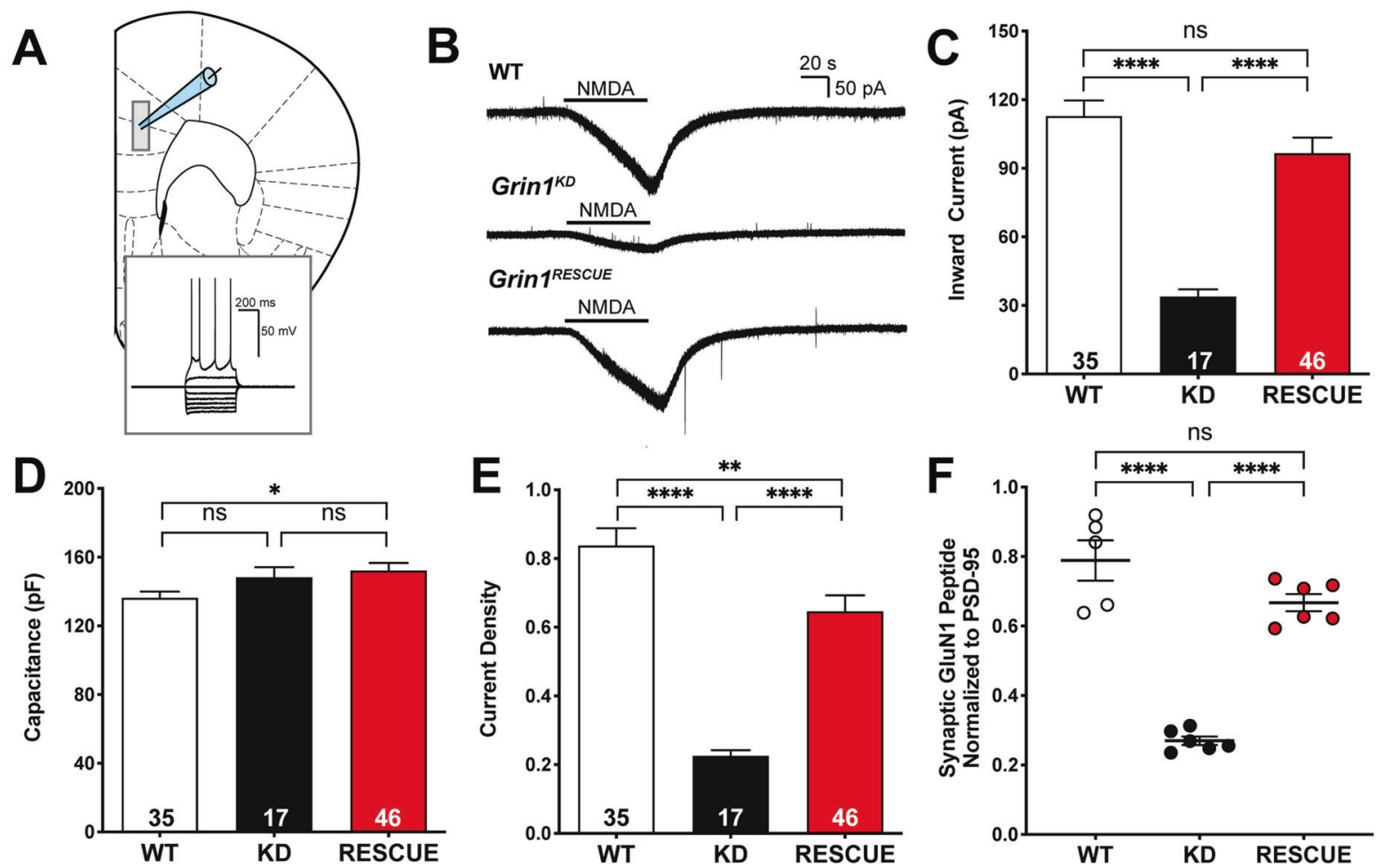

Fig. 3 NMDAR currents and synaptic GluN1 peptide levels are restored in the mPFC of Grin1 ${ }^{R E S C U E}$ mice. a Schematic of mPFC with whole cell patch clamp recording from layer $\mathrm{V}$ adapted from [48]. Inset: electrophysiological signature of Grin1 $1^{R E S C U E}$ layer V pyramidal neuron. b Representative traces in voltage clamp $(-75 \mathrm{mV})$ showing prefrontal response to NMDA across the three genotypes (number of layer V pyramidal neurons shown, 5-6 mice per genotype). c Quantification of peak amplitude of prefrontal NMDAR-elicited currents. One-way ANOVA, effect of genotype, $F_{2,95}=22, p<0.0001$,

Bonferroni post hoc. d Capacitance of prefrontal layer V pyramidal neurons. One-way ANOVA, Bonferroni post hoc. e Current density of prefrontal NMDA-elicited currents. One-way ANOVA, effect of genotype, $F_{2,95}=3.6, p=0.03$, Bonferroni post hoc. f Synaptic GluN1 peptide (IVNIGAVLSTR) levels in the PFC. One-way ANOVA, effect of genotype, $F_{2,14}=64.76, p<0.0001$, Bonferroni post hoc. All data shown as mean \pm SEM, $* p<0.05 ; * * p<0.01$; *** $p<0.001$; **** $p<$ 0.0001 , ns not significant.

spectrometry. This procedure isolates the proteins that are part of the PSD-95 post-synaptic protein complex. Specifically, the amount of GluN1 peptide IVNIGAVLSTR was determined relative to the intensity of PSD-95 peptides, to indicate the abundance of GluN1 protein at PFC synapses. As shown in Fig. 3f, GluN1 peptide throughout the PFC was reduced in Grinl ${ }^{K D}$ mice and restored to wild-type levels in Grin $1^{R E S C U E}$ mice (WT: $0.79 \pm 0.06$, Grinl $^{\text {RESCUE }}$ : $0.67 \pm 0.02, p=0.077$, power $=1.00$ ).

\section{Cognitive impairments are rescued by adult intervention}

We studied several domains of cognition that are used as endophenotypes for autism related neurodevelopmental disorders: habituation to a novel environment, sensory processing of acoustic startle, executive function, social interaction, and anxiety. Although each of these behaviours relies on more than cortical function for their performance, previous studies have repeatedly demonstrated the critical role that the PFC plays in these cognitive tasks. Indeed, cellselective knockout of NMDARs in cortical neurons is sufficient to impair habituation, sensory processing of acoustic startle, social interaction, and anxiety [19-21].

Habituation to a novel environment requires the cortical and hippocampal processes of working and spatial memory to reduce exploration activity after a period of time [22, 23]. Habituation was quantified by calculating the habituation index (H.I.), which is the time required to reach half of the maximal locomotor activity using linear regression. Grin $1^{K D}$ mice showed initial hyperactivity relative to WT in the first $10 \mathrm{~min}$ of exploration, and $120 \mathrm{~min}$ later, these mutant mice continued to explore the arena with high levels of activity (extrapolated H.I.: $149.1 \pm 15.6 \mathrm{~min}$; Fig. $4 \mathrm{a}-\mathrm{c}$ ). In contrast, while Grinl ${ }^{R E S C U E}$ rescue mice also showed initial hyperactivity, their habituation to the novel environment was similar to WT mice (H.I.: WT $53.5 \pm 1.2 \mathrm{~min}$, Grinl $1^{R E S C U E}$ $64.4 \pm 3.2 \mathrm{~min}$; Fig. $4 \mathrm{a}-\mathrm{c}, p>0.99$, power $=1.00$ ).

While assessing novelty-induced locomotion, we simultaneously measured stereotypy, an endophenotype of the repetitive 

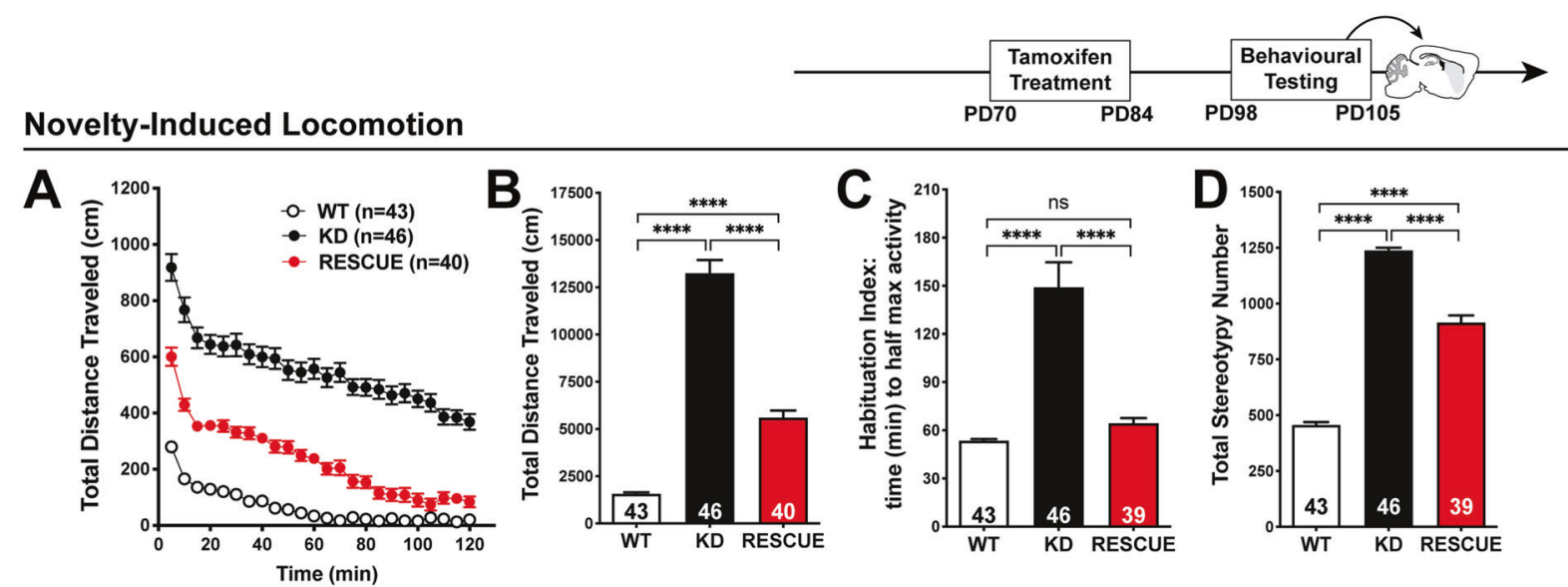

Pre-Pulse Inhibition (Sensorimotor Gating)

E $\square \mathrm{WT} \square$ Grin1 $^{\mathrm{KD}} \square$ Grin1 $^{R E S C U E} \mathbf{F}$
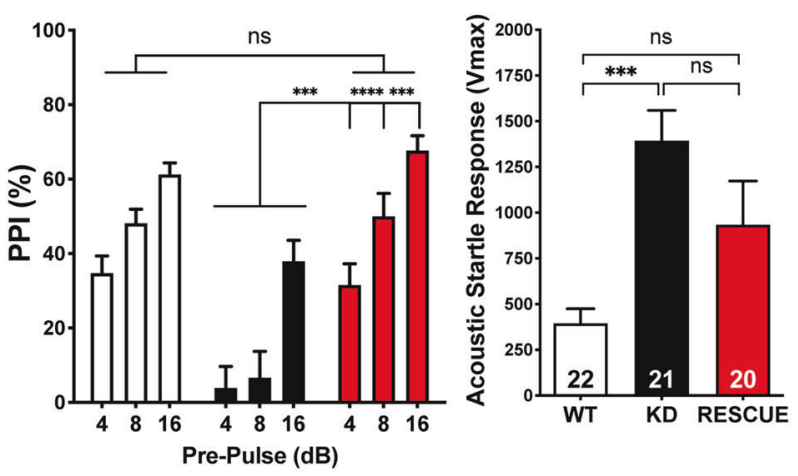

Social Behaviour
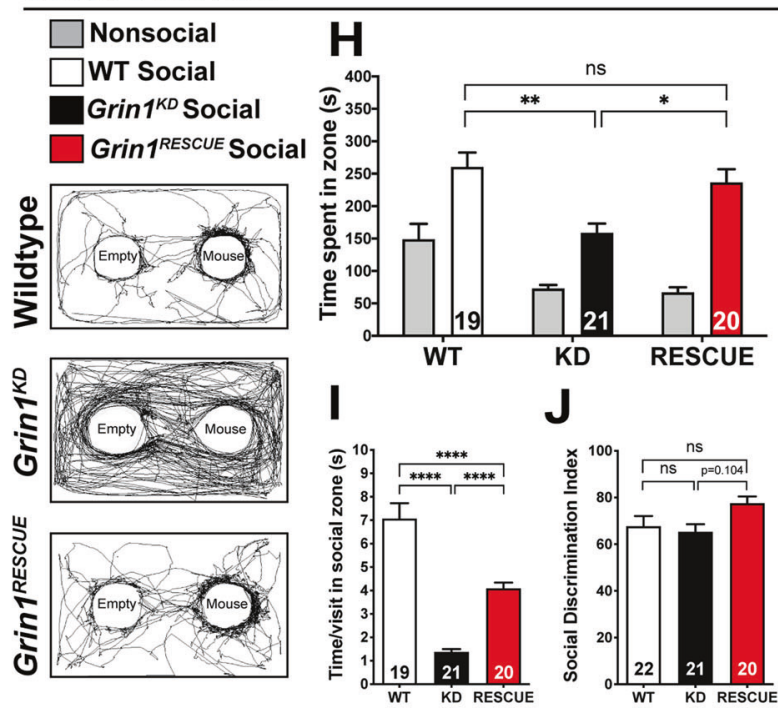

\section{Puzzle Box (Executive Function)}
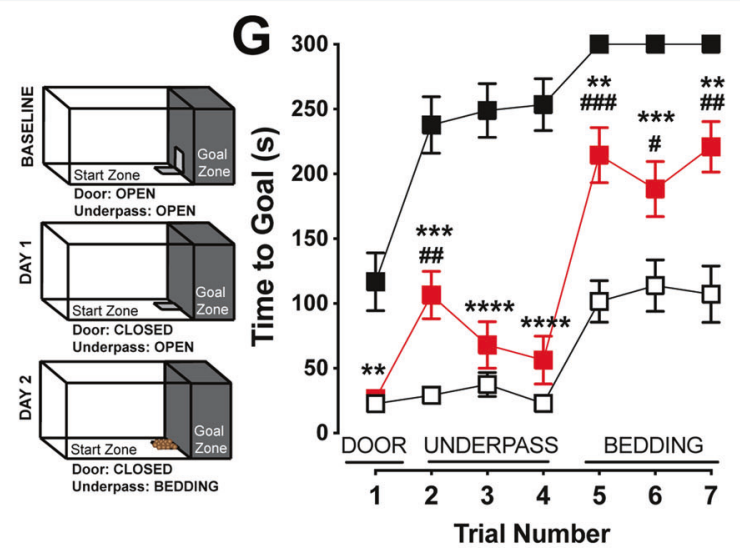

Elevated Plus Maze (Anxiety-Like)

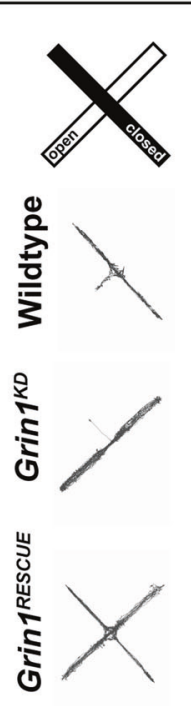

Closed Arms Grin1 ${ }^{K D}$ Open Arm $\square$ WT Open Arm $\square$ Grin1 ${ }^{R E S C U E}$ Open Arm
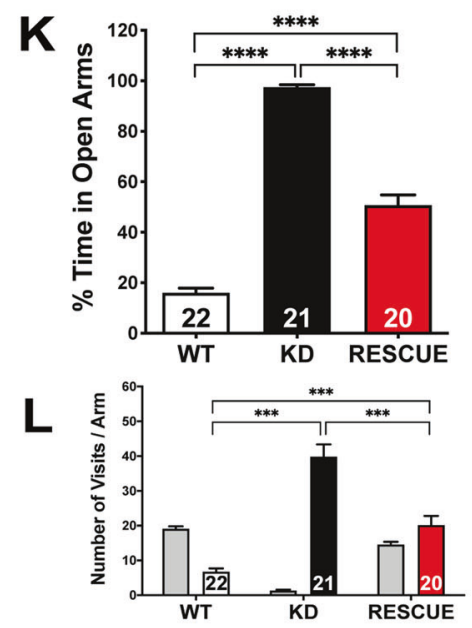

behaviours that are observed in GRIN disorder. Grin ${ }^{K D}$ mice display increased stereotypy that is $250 \%$ of WT levels (Fig. 4d). Grin $1^{R E S C U E}$ mice displayed only a modest improvement in stereotypy that is still $180 \%$ of WT (Fig. 4d), in contrast to the substantial improvements observed for habituation.
Sensorimotor gating, which is modulated by cortical arousal circuits [24], was measured with the paradigm of pre-pulse inhibition (PPI) of acoustic startle response (ASR). Consistent with studies of the original knockdown mutation [25], Grin ${ }^{K D}$ mice exhibited deficits in 
Fig. 4 Cognitive function rescued with adult intervention, while other behaviours show intermediate improvement. All behaviours were measured in WT, Grin $1^{K D}$, and Grinl $1^{R E S C U E}$ mice starting at PD98. a Time course and $\mathbf{b}$ total distance travelled $(\mathrm{cm})$ in open field (OF) test. One-way ANOVA (total, effect of genotype $F_{2,126}=156.3$, $p<0.0001$ ), Bonferroni post hoc. c Habituation index (time to reach half maximal activity) in OF test. One-way ANOVA, effect of genotype, $F_{2,125}=29.38, p<0.0001$, Bonferroni post hoc. d Stereotypy number in OF test. One-way ANOVA, effect of genotype, $F_{2,126}=$ 382.7, $p<0.0001$, Bonferroni post hoc. e Percent inhibition of startle response (pre-pulse inhibition, PPI). Shown on graph, Grin1 ${ }^{K D}$ vs. Grin $1^{R E S C U E}$, two-way ANOVA, effect of genotype- $-F_{2,60}=16.65$, $p<0.0001$; genotype $\times$ decibel $-F_{4,120}=3.526, p=0.0093$, Bonferroni post hoc. f Acoustic startle response (ASR). One-way ANOVA, effect of genotype, $F_{2,60}=8.913, p=0.0004$, Bonferroni post hoc. g Time to reach goal zone (seconds; max $300 \mathrm{~s}$ ) measured in puzzle box paradigm. Shown on graph, "WT vs. Grinl ${ }^{\text {RESCUE}}$; ${ }^{*}$ Grinl ${ }^{K D}$ vs. Grin1 ${ }^{R E S C U E}$. Two-way ANOVA, effect of genotype: $F_{2,64}=66.98$, $p<0.0001$, Bonferroni post hoc. $n$ values: WT-21, Grin1 ${ }^{K D}-25$, Grin1 ${ }^{R E S C U E}-21$. h Total time spent, $\mathbf{i}$ time per visit and $\mathbf{j}$ social discrimination index in zones during 10 min modified three chamber social test. One-way ANCOVA, there is an effect of genotype after controlling for locomotor activity: (time in social zone) $F_{2,59}=4.707$, $p=0.013$, (time/visit) $F_{2,59}=4.424, p=0.016$, (discrimination index) $F_{2,59}=3.161, p=0.050$, Bonferroni post hoc. $\mathbf{k} \%$ time spent in open arms and $\mathbf{l}$ number of visits per arm in the elevated plus maze (EPM). One-way ANCOVA, there is an effect of genotype after controlling for locomotor activity: (\% time spent in open arms) $F_{2,59}=280.024, p<$ 0.001 , (number of visits in the open arm) $F_{2,59}=134.631, p<0.001$, Bonferroni post hoc. All data shown as mean \pm SEM, ${ }^{*} p<0.05$; $* * p<$ $0.01 ; * * * p<0.001 ; * * * * p<0.0001$, ns not significant.

sensorimotor gating at pre-pulse intensities of 4,8 , and 16 $\mathrm{dB}$ (Fig. 4e). This indicated that the pre-cognitive ability to attenuate motor response to a startling sound was impaired. Grin $1^{\text {RESCUE }}$ mice showed a complete restoration of sensory processing in this test, with PPI levels that were similar to WT littermates (Fig. 4e, $p>0.99$, power $>0.99$ ). Interestingly, although PPI was normalised in the Grinl $1^{\text {RESCUE }}$ mice, the genetic intervention had little effect on the amplitude of the startle reflex itself. Both $\operatorname{Grin1} 1^{K D}$ and Grin $1^{\text {RESCUE }}$ mice had a similar exaggeration in their startle amplitude that was $330 \%$ and $250 \%$ of WT, respectively (Fig. 4f).

Executive function was tested in the puzzle box test, which measured the ability of the mouse to overcome increasingly challenging obstacles and reach a goal box. Mice were first introduced to the arena with an open doorway leading to the goal, but on subsequent tests the doorway was blocked, and mice had to use an underpass or dig through bedding to reach the goal. Thus, the test measured goaldirected behaviour and cognitive flexibility to respond to different challenges [26]. Grinl ${ }^{K D}$ mice performed markedly worse than WT in early trials, taking 4-5 times longer to reach the goal box, and routinely failed the most challenging task of digging through bedding (Fig. 4g). Impressively, Grinl $1^{\text {RESCUE }}$ mice solved both challenges, and performed significantly better than Grinl ${ }^{K D}$ mice on all trials (Fig. $4 \mathrm{~g}$ ).
Indeed, in three of the seven trials, Grin $1^{\text {RESCUE }}$ mice performed similar to WT mice. Thus, there were substantial improvements in executive function as assessed in the puzzle box test.

Affiliative social behaviour was studied by measuring the amount of time that a mouse spent investigating a novel $\mathrm{C} 57 \mathrm{Bl} / 6 \mathrm{~J}$ mouse. The novel mouse was constrained in one area with a wire cage, and an empty cage was included in the arena to control for non-social investigation of the cage. As expected, social interaction was significantly impaired in Grin $1^{K D}$ mice relative to WT, controlling for locomotor activity (Fig. 4h). Grin1 $1^{\text {RESCUE }}$ mice displayed social interaction that was completely restored to WT levels $(p>$ 0.99 , power $=1.00$ ). Not only was the amount of time spent in social interaction normalised in Grinl $1^{R E S C U E}$ mice, but the quality of social interaction appeared to improve, as demonstrated by the longer time spent with each visit to the novel mouse (Fig. 4i). While there were genotype differences in the amount of time spent in social interaction, all three genotypes of mice showed a similar preference for social investigation over non-social investigation of the empty cage, as reflected in a similar discrimination index between genotypes (Fig. 4j). Thus the improvement in social interaction reflected an improved quality of social interaction rather than a change in social motivation.

Lastly, we measured anxiety-like behaviour in the elevated plus maze. WT mice spent less than $20 \%$ of time in the open arms of the maze; in contrast, $\operatorname{Grin} 1^{K D}$ mice spent nearly $100 \%$ of time in the open arms (Fig. 4k). In this behavioural domain, the Grin1 $1^{\text {RESCUE }}$ mice showed an intermediate phenotype, spending $50 \%$ of time in the open arms of the maze. The amount of time spent in the open arms by each genotype is further confirmed in the number of entries observed into the open arm (Fig. 41). The three genotypes had a similar number of total arm entries (Fig. 41), and ANCOVA analysis to control for differences in locomotor activity still showed a significant effect of genotype.

We observed similar patterns of behavioural deficits in male and female $G r i n 1^{K D}$ mice, and similar patterns of recovery in Grin1 $1^{\text {RESCUE }}$ male and female mice in most tests. There were notable sex differences in a select behavioural test, the puzzle box test: for all three genotypes, female mice performed better than male mice of the same genotype (Supplementary Fig. 5).

It should also be noted that, in the puzzle box test, the female Grinl $1^{\text {RESCUE }}$ mice showed a greater improvement than male Grin $1^{\text {RESCUE }}$ mice (Supplementary Fig. 5).

In summary, our battery of behavioural tests pointed to the most effective rescue of cognitive functions that included habituation to novelty, sensorimotor gating, executive function, and social investigation. Intermediate levels of rescue were observed for the initial hyperlocomotor 
response to novelty and anxiety-like behaviour. Minimal rescue was observed for stereotypy and the acoustic startle reflex response.

\section{Cognitive improvements persist with a longer recovery period}

Finally, we asked whether these behavioural improvements would persist or would further improve with a longer recovery period. We also hypothesised that a longer recovery period might be necessary for those behaviours that were not robustly improved after only 2 weeks. Therefore, in a distinct cohort of experimental and control mice, we induced Cre-mediated rescue of Grin1 at PD70, as in the original paradigm, but waited an additional 4 weeks before testing the animals (6-week recovery vs. original 2week recovery). In this cohort, there was a similar degree of rescue in the level of NMDARs (Supplementary Table II). Behaviourally, the Grin1 $1^{R E S C U E}$ mice showed significant improvement across all measures examined (Fig. 5), in a pattern consistent with the assessments presented in Fig. 4. Grin ${ }^{R E S C U E}$ mice, treated at PD70, and allowed to recover for 6 weeks, showed improvement in their sensorimotor gating (PPI, Fig. 5d), executive function (EF, Fig. 5f), and affiliative social behaviour (AS, Fig. $5 \mathrm{~g}$ ), that was similar to WT (PPI: $(4 \mathrm{~dB}) p=0.072$, power $=1.00,(8 \mathrm{~dB}) p=1.00$, power $=0.99$, $(16 \mathrm{~dB}) p=1.00$, power $=0.94 ; \mathrm{EF}: p>$ 0.05 , power $=1.00 ;$ AS: $p>0.99$, power $=0.99$ ). These experiments indicate that adult intervention leads to sustained cognitive improvement that can be observed as early as 2 weeks after completion of treatment.

There were also indications of sustained improvements in overall health, since deficits in body mass were normalised after 6 weeks of recovery (Supplementary Fig. 6). However, the longer recovery period did not provide greater levels of improvement in "rescue-refractory" behaviours: initial locomotor hyperactivity (Fig. 5a, b), stereotypy (Fig. 5c), ASR (Fig. 5e), or anxiety-like behaviour (Fig. 5h). Therefore, we also conducted experiments where genetic rescue was initiated at earlier stages of development, focusing on some of the "rescue-refractory" behaviours to determine whether earlier stages of intervention were necessary. The same tamoxifen administration regimen was given to mice at 3- and 6- weeks of age (PD21 or PD42), and the mice were allowed to age until PD98 (Fig. 6). There was no benefit to earlier treatment at PD42 in domains of locomotor hyperactivity, acoustic startle, or anxiety (Fig. 6c, d, g, h; interaction of genotype $\times$ intervention: (locomotor) $F_{2,251}=1.704, p=0.184$, (acoustic startle) $F_{2,121}=3.001, p=0.053$, (EPM) $F_{2,121}=2.028, p=0.136$, post hoc showing no difference between interventions within Grinl $\left.{ }^{\text {RESCUE }}, p>0.05\right)$. However, treatment at PD21 did provide more substantial improvements in anxiety-like behaviours (Fig. 6f), when compared to adult intervention (PD70; Fig. 4k) (interaction of genotype $\times$ intervention: $\left.F_{1,86}=18.631, p<0.001\right)$, and post hoc analysis showed this was significant for the Grinl ${ }^{R E S C U E}(p<0.001)$ but not the $\operatorname{Grin} 1^{K D}$ or WT ( $p=1.000$ for both).

\section{Discussion}

The knockdown of Grinl results in viable mutant mice with deficits in cognitive behaviours that parallel the symptoms of GRIN1 encephalopathy [13]. We did not find evidence of any deleterious effects from the postnatal upregulation of NMDARs. Grin $1^{R E S C U E}$ mice had healthier coats, reached normal body weights, and were less reactive to handling after Cre induction. We found improvements in nearly every aspect of behaviour that we examined.

Our strategy to achieve temporal rescue of NMDARs took advantage of a tamoxifen-inducible Cre recombinase [27]. The study design allowed us to treat all groups of mice with tamoxifen, reducing the likelihood that the behavioural recovery of Grinl $1^{\text {RESCUE }}$ mice would be obscured by the drug treatment. Vogt et al. showed that a 4-week washout period was sufficient to avoid tamoxifen's effects on cognition [28]. We observed that the biochemical and behavioural measures were remarkably similar with a 2- or 6week washout (Figs. 4, 5, Supplementary Fig. 3, Table II), suggesting that tamoxifen had little effect on our measures of recovery.

This study focused primarily on the question of whether or not any recovery of neurodevelopmental deficits was possible, and if so, when in development must an intervention occur. Our results show that remarkable recovery is possible in adulthood and that similar outcomes occur in both the adolescent and adult brain. Future studies will determine whether recovery leads to a replenishment of white matter volumes and synapse number, since NMDAR deficient mice have white matter deficits [29] and reduced synapse density in the cortex and striatum [30, 31]. Studies of the molecular and cellular events that occur with recovery could provide insight into the means by which the brain rewires and recovers from a neurodevelopmental insult.

One limitation to the full recovery of all behavioural abnormalities was the cellular and regional differences in the normalisation of Grinl mRNA that were achieved in Grinl $1^{\text {RESCUE }}$ mice. Indeed, the behaviours associated with striatum function, such as hyperactivity and stereotypy, were not completely normalised in Grinl $1^{R E S C U E}$ mice. This is likely due to the limited increase in Grinl mRNA and NMDAR function in that brain region (Supplementary Fig. 7, Table II, III). Even within the cortex, we observed variability in the levels of rescue. We noted in Grinl ${ }^{R E S C U E}$ mice that glutamatergic cells, which have a more open chromatin 

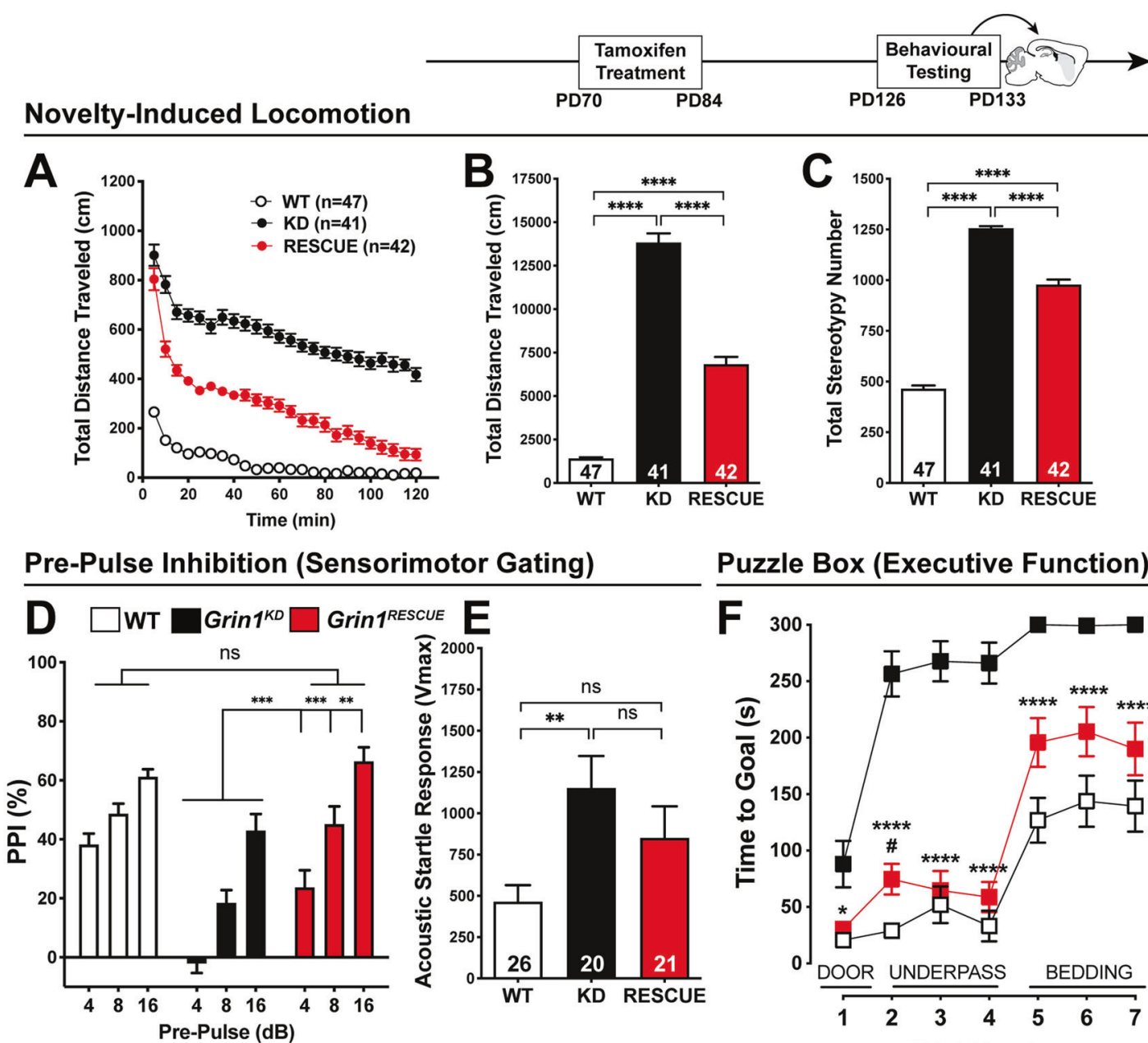

Puzzle Box (Executive Function)

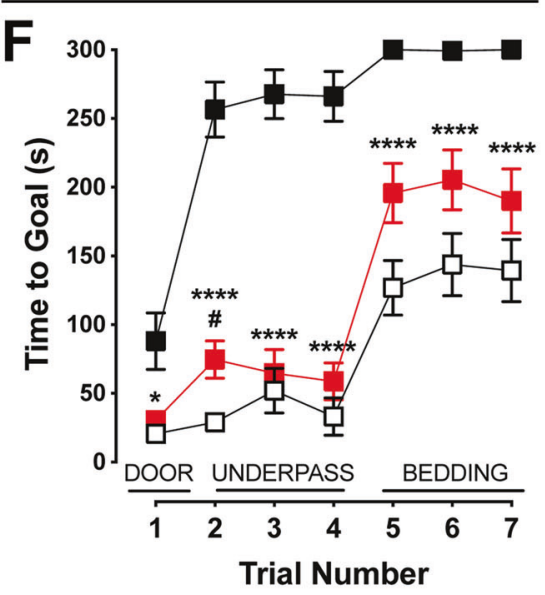

\section{Social Behaviour}

Elevated Plus Maze (Anxiety-Like)
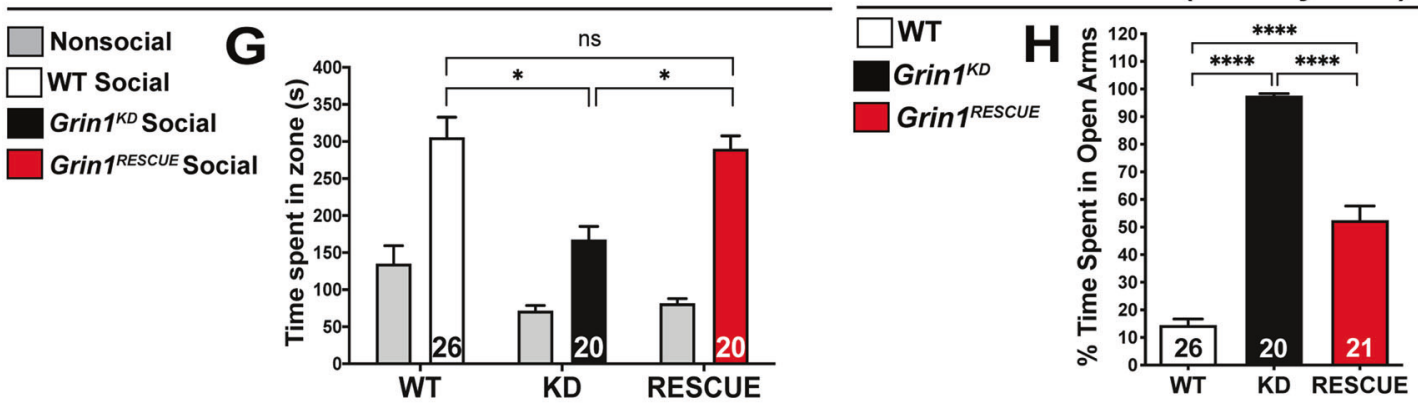

Fig. 5 Replicable and robust cognitive function improvement with adult intervention (PD70) and extended recovery time. All behaviours were measured in WT, Grinl $1^{K D}$, and Grinl ${ }^{R E S C U E}$ mice starting at PD126. a Time-course and $\mathbf{b}$ total distance travelled $(\mathrm{cm})$ in open field (OF) test. One-way ANOVA (total, effect of genotype $F_{2,127}=$ 276.0, $p<0.0001$ ), Bonferroni post hoc. c Stereotypy number in $\mathrm{OF}$ test. One-way ANOVA, effect of genotype, $F_{2,127}=506.7, p<0.0001$, Bonferroni post hoc. d Percent inhibition of startle response (pre-pulse inhibition, PPI). Shown on graph, Grin1 ${ }^{K D}$ vs. Grin1 $1^{R E S C U E}$, two-way ANOVA, effect of genotype $-F_{2,64}=15.81, p<0.0001$; genotype $\times$ decibel $-F_{4,128}=7.060, p<0.0001$, Bonferroni post hoc. e Acoustic startle response (ASR). One-way ANOVA, effect of genotype, $F_{2,64}=$ 4.873, $p=0.0107$, Bonferroni post hoc. f Time to reach goal zone (seconds; max $300 \mathrm{~s}$ ) measured in puzzle box paradigm. Shown on graph, "WT vs. Grin1 ${ }^{\text {RESCUE; }}{ }^{*}$ Grin $1^{\text {KD }}$ vs. Grin $1^{\text {RESCUE. Two-way }}$ ANOVA, effect of genotype: $F_{2,61}=60.36, p<0.0001$, Bonferroni post hoc. $n$ values: WT-21, Grin1 ${ }^{K D}-21$, Grin1 $1^{R E S C U E}-22$. $\mathbf{g}$ Total time spent in zones during $10 \mathrm{~min}$. modified three chamber social test. One-way ANCOVA, there is an effect of genotype after controlling for locomotor activity on time spent in the social zone, $F_{2,63}=4.061, p=$ 0.022 , Bonferroni post hoc. $\mathbf{h} \%$ time spent in open arms in the elevated plus maze (EPM). One-way ANCOVA, there is an effect of genotype on \% time spent in open arms after controlling for locomotor activity, $F_{2,63}=156.537, p<0.001$, Bonferroni post hoc. All data shown as mean \pm SEM, ${ }^{*} p<0.05 ; * * p<0.01 ; * * * p<0.001$; **** $p<$ 0.0001 , ns not significant. 


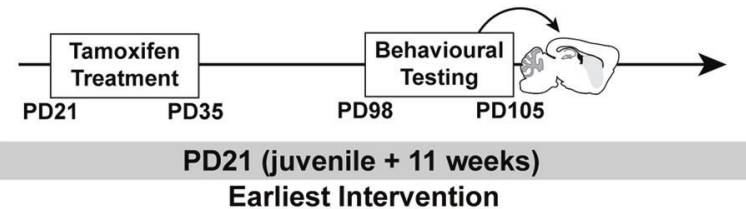

Earliest Intervention

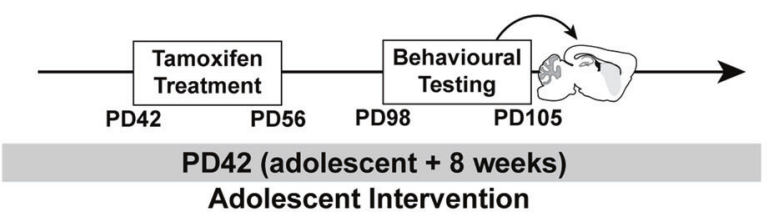

Adolescent Intervention

\section{Novelty-Induced Locomotion}
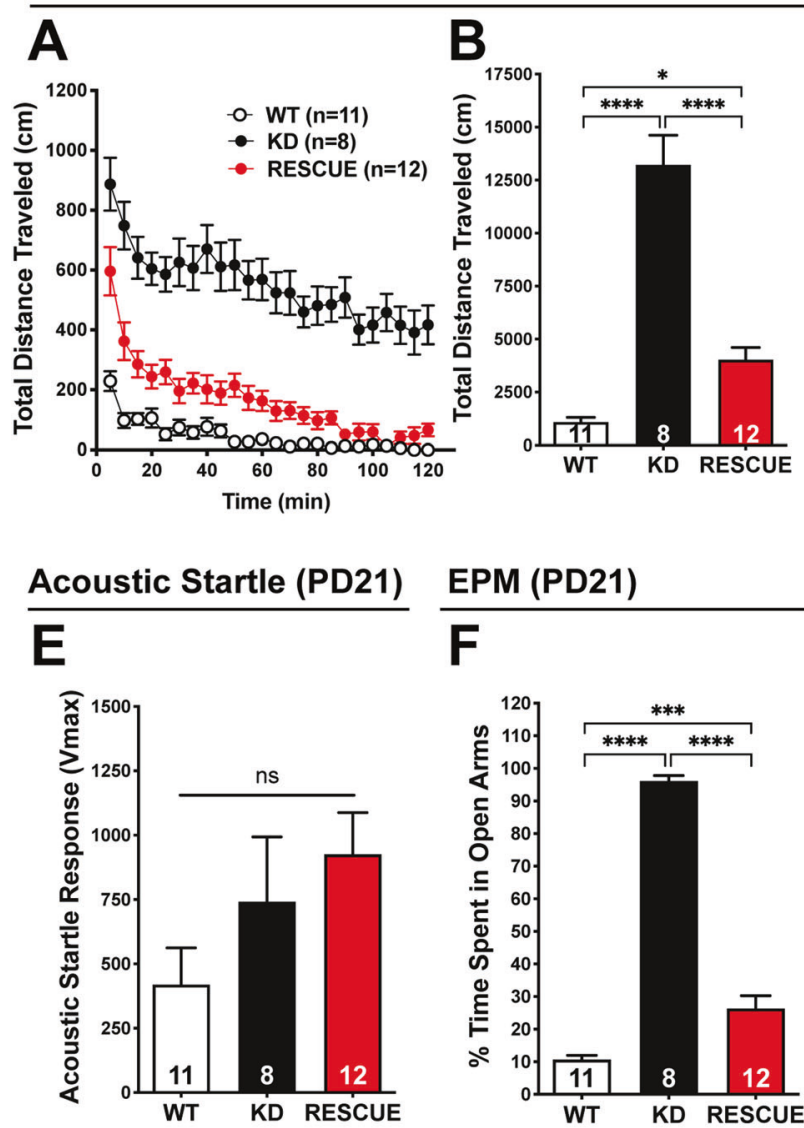

Fig. 6 Effect of early intervention on behaviours that are rescuerefractory with adult intervention. All behaviours were measured in $\mathrm{WT}$, Grin $1^{K D}$, and Grin $1^{R E S C U E}$ mice starting at PD126, following intervention at either PD21 (left), or PD42 (right). a, c Time-course and $\mathbf{b}, \mathbf{d}$ total distance travelled $(\mathrm{cm})$ in open field $(\mathrm{OF})$ test. One-way ANOVA, total distance travelled, effect of genotype: (PD21) $F_{2,28}=$ 62.53, $p<0.0001$, (PD42) $F_{2,125}=202.7, p<0.0001$, Bonferroni post

structure at Grinl, had a more consistent expression of Grinl than GABAergic cells, which have a more closed chromatin structure at that locus. Therefore, we hypothesise that regional and cellular differences in recovery are influenced by chromatin accessibility, which should be considered in the context of future gene-editing therapies.

In spite of these limitations, our results provide striking evidence of the plasticity of the adult brain, particularly in the cortex. Within the cortex the highest levels of recovery were observed in Vglut $1+$ cells, which normally express the highest levels of Grin1 [16]. It is possible that very early interventions would provide a more complete recovery in some cell types or brain functions. However, our results
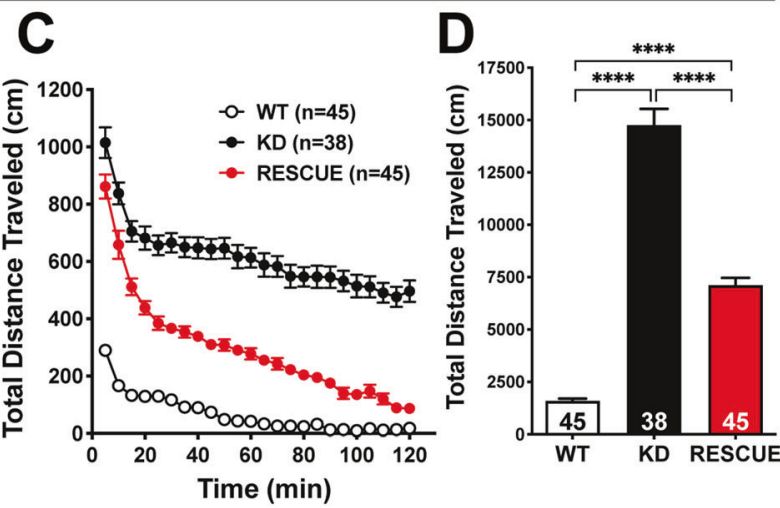
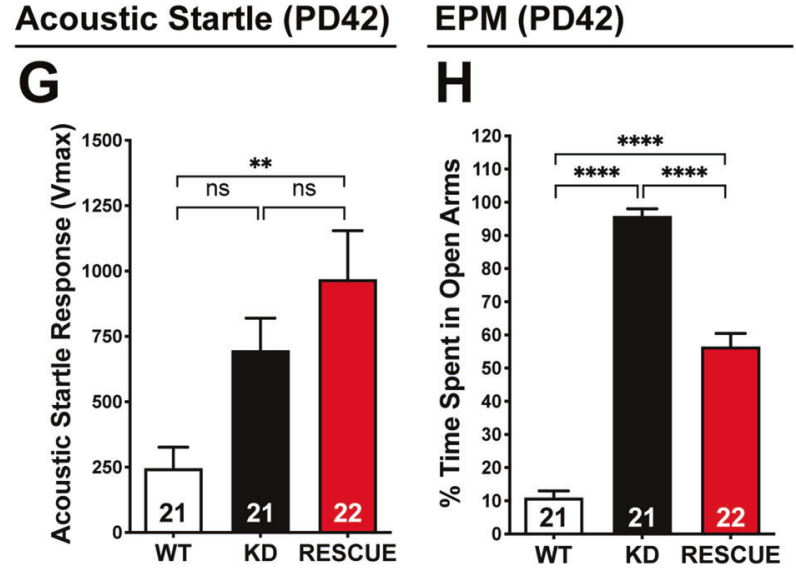

hoc. e, $\mathbf{g}$ Acoustic startle response (ASR). One-way ANOVA, effect of genotype, (PD21) $F_{2,28}=2.249, p=0.1242$, (PD42) $F_{2,61}=6.975$, $p=0.0019$, Bonferroni post hoc. $\mathbf{f}, \mathbf{h}$ Percent time spent in open arms in the elevated plus maze (EPM). One-way ANOVA, effect of genotype, (PD21) $F_{2,28}=219.1, p<0.0001$, (PD42) $F_{2,61}=210.9, p<$ 0.0001 , Bonferroni post hoc. All data shown as mean \pm SEM, $* p<$ $0.05 ; * * p<0.01 ; * * * p<0.001 ; * * * * p<0.0001$, ns not significant.

suggest that symptoms of intellectual disability, a consistent symptom of GRIN disorder [4], can be largely treated with adult intervention. This is particularly surprising since cognitive impairments are refractory to current pharmacological treatment in patients with autism and schizophrenia [32], two conditions associated with impaired NMDAR function [33]. Adult genetic reversal has an even greater clinical impact, as it offers the possibility of stable restoration of normal function even after the brain has completed development [34, 35].

The prevalence of pathogenic variants has been estimated at 5.45 per 100,000 births for GRIN1, and 3.23 and 5.91 per 100,000 for GRIN2A and GRIN2B respectively [36, 37]. The 
first patients to be sequenced had diagnoses of intellectual disability [38] or epilepsy [13]. A recent whole-exome sequencing study reported that $7 \%$ of patients with autism or schizophrenia carry a predicted-deleterious coding mutation in one of six GRIN genes (25/370 patients with schizophrenia, 15/192 patients with autism) [39]. There have also been numerous genetic and epidemiological studies supporting a causal role for NMDARs in several neuropsychiatric disorders. Thus, the significance of our findings is not limited to those patients who have been sequenced to date.

This study highlights the significant potential of therapeutic intervention in adult patients. It demonstrates that a delay between symptom onset and treatment can be overcome. The cognitive symptoms of neuropsychiatric and neurodevelopmental conditions caused by NMDAR hypofunction are amenable to treatment and show persisting improvement. The mature cortex has sufficient plasticity to recover from insults to this key developmental system, and adult intervention with the appropriate therapeutic agent should treat intellectual disabilities.

\section{Materials and methods}

\section{Animals}

Animal housing and experimentation were carried out in accordance with the Canadian Council in Animal Care guidelines for the care and use of animals and following protocols approved by the Faculty of Medicine and Pharmacy Animal Care Committee at the University of Toronto. Mice were group housed with littermates on $12 \mathrm{~h}$ light-dark cycle and were given ad libitum access to water and food.

ROSA26 $6^{\text {CrEERT2 }}$ mice were obtained from Jackson Labora-

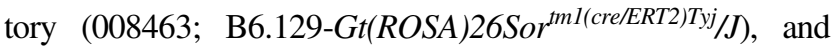
were previously described [27]. The Cre-reporter mouse line used, ROSA26 $6^{\text {tdTomato }}$, was obtained from Jackson Laboratory

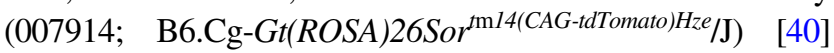
and was crossed with the ROSA26 $6^{\text {CreERT2 }}$ line.

Grin $1^{\text {fneo/fneo }}$ mice were generated at the University of Toronto, based on the previously described Grinl $1^{\text {neo/neo }}$ mouse [15]. Identical to the Grinl ${ }^{\text {neo/neo }}$ model, the Grinl gene was modified via homologous recombination with an intervening sequence (neomycin cassette), and targeted into intron 19, flanked by loxP sites (pXena vector; gift of Dr. Beverly Koller).

Grin1 $1^{+/ \text {flneo }}$ :CreTg mice were produced by crossing ROSA26 $6^{\text {CreERT2 }} \mathrm{C} 57 \mathrm{Bl} / 6 \mathrm{~J}$ congenic mice to Grin1 ${ }^{+/ \text {flneo }}$ $\mathrm{C} 57 \mathrm{~B} 1 / 6 \mathrm{~J}$ congenics. The resulting compound heterozygotes were bred to Grin $1^{+/ \text {flneo }} 129 / \mathrm{SvlmJ}$ congenics to produce the F1 progeny used for all experiments as recommended by the Banbury Conference [41]. Experimental mice of the F1 background were: Grinl ${ }^{+/+}$(WT), Grinl ${ }^{+/+}:$CreTg
(WTCre), Grinl $1^{\text {fneo/flneo }}\left(G r i n 1^{K D}\right)$, and Grin1 ${ }^{+/ \text {flneo }}:$ CreTg $\left(\right.$ Grin $\left.1^{\text {RESCUE }}\right)$.

\section{Tamoxifen administration}

Tamoxifen was administered to all genotypes of mice (WT, WTCre, Grinl $1^{K D}$, Grinl $1^{\text {RESCUE}}$ ). Tamoxifen (T5648, Sigma-Aldrich, St. Louis, MO, USA) was administered via oral gavage $(6 \mathrm{mg}, 20 \mathrm{mg} / \mathrm{ml}$ dissolved in $100 \%$ corn oil at $65^{\circ} \mathrm{C}$ for $1 \mathrm{~h}$ ) on day 1 of treatment, and then mice were given tamoxifen chow (TD.140425, 500 mg/kg, Envigo) ad libitum for 14 days.

\section{Behavioural testing}

Male and female mice of equal numbers were used for behavioural testing. Tests were administered at PD98 or PD126. All experimental animals were first tested for locomotor activity on day 1 . Mice were then assigned to one of two groups for subsequent behavioural tests that spanned 3 days. The puzzle box test [26] was administered to mice in Group A over days 2-4. Mice in Group B were tested in elevated plus maze on day 2 , social affiliative paradigm on day 3 , and PPI of acoustic startle on day 4, as previously described [42-45].

\section{Fluorescent in situ hybridisation}

Expression of Grin1, Vglut1, and Gad1 mRNA in WT, $G \operatorname{rin} 1^{K D}$, and Grin1 $1^{R E S C U E}$ mice was visualised by RNAscope Multiplex Fluorescent Reagent Kit v2 protocol (ACD Bio; CA, USA). Fresh frozen mouse brains were used to collect $20 \mu \mathrm{m}$ sagittal sections $(1.2$ and $1.53 \mathrm{~mm}$ from midline). Sections were hybridised to Grinl probes (\#533691-C1, ACD Bio) and Vglut1 probes (\#416631-C2), to Grinl probes and Gadl probes (\#400951-C3) or to control probe mixtures (positive control probes \#320881, negative control probes \#320871). Processed slides were imaged at 20X magnification with an Axio Scan.Z1 slide scanner (Zeiss, Oberkochen, DEU) or 40X magnification with an AxioObserverZ1 Inverted Motorised Microscope.

\section{Re-analysis of publicly-accessible single-cell and cell type-specific genomics data}

We obtained single-cell RNAseq data sampled from the adult mouse visual cortex via the Allen Institute for Brain Science's Cell Types database (http://celltypes.brain-map. org/) [16] and pooled cell type-specific ATACseq (Assay for Transposase-Accessible Chromatin) data sampled by the Allen Institute for Brain Sciences from the adult mouse visual cortex from the Gene Expression Omnibus repository (GSE87548) [18]. 


\section{GluN1 immunofluorescent visualisation}

Expression of GluN1 protein levels in WT, Grinl ${ }^{K D}$, and Grinl ${ }^{\text {RESCUE }}$ mice were on fresh frozen sagittal tissue sections $(20 \mu \mathrm{m}$ thick; Lateral $\sim 1.92 \mathrm{~mm})$. Sections were incubated with an in-house rabbit anti-GluN1 antibody raised against peptide ETEKPRGYQMSTRLK (C) (1:200), and then with secondary antibody, anti-rabbit Alexa 568 (ThermoFisher, \#A11011, 1:500).

\section{$\left[{ }^{3} \mathrm{H}\right] \mathrm{MK}-801$ saturation binding}

NMDAR levels in WT, Grinl $1^{K D}$, and Grinl $1^{\text {RESCUE }}$ mice were quantified in prefrontal cortical and striatal tissue. The following solutions were prepared: membranes, $1.6 \mu \mathrm{g} / \mu \mathrm{l}$ working concentration; $\left[{ }^{3} \mathrm{H}\right] \mathrm{MK}-801$ (Perkin Elmer), 120 $\mathrm{nM}$ working concentration; and cold MK-801 (SigmaAldrich), $1200 \mathrm{nM}$ working solution (10× $\left.\left[{ }^{3} \mathrm{H}\right] \mathrm{MK}-801\right)$. Binding assays were performed with the NMDAR antagonist MK-801 (hot and/or cold), mouse brain membranes (80 $\mu \mathrm{g}$ ) and binding buffer (total binding vs. non-specific binding), with a total assay volume of $150 \mu$. Radioactivity was quantified via liquid scintillation spectrometry [46].

\section{PSD-95 immunoprecipitation mass spectrometry}

As previously described [47], mouse anti-PSD-95 antibody (Millipore, catalogue \# MAB1596) was used to capture PSD95 protein complexes from flash frozen cortex samples (3 males and 3 females of each genotype were used). $5 \mu \mathrm{g}$ of PSD-95 antibody was coupled per $1 \mathrm{mg}$ of Dynabeads (Life Technologies; antibody coupling kit protocol (\#14311D). The data was recorded using Analyst-TF (version 1.7) software and analyzed by Sciex DIA software to generate peptide intensities.

\section{Electrophysiological recordings}

Coronal slices $(400 \mu \mathrm{m})$ of the mPFC $(1.98-1.34 \mathrm{~mm}$ [12]) and caudate putamen $(1.54-0.14 \mathrm{~mm})$ were used. Most experiments were performed in the presence of CNQX disodium salt ( $20 \mu \mathrm{m}$; Alomone Labs) to block AMPA receptors. NMDA (30 $\mu \mathrm{m}$; Sigma-Aldrich) was bath applied. Application of APV $(50 \mu \mathrm{M}$; Alomone Labs) confirmed the inward currents were mediated by NMDARs. Peak amplitude of the NMDA currents was measured using Clampfit software (Molecular Devices). Magnitude of NMDA-elicited inward currents was quantified by subtracting a $1 \mathrm{~s}$ average holding current at the peak from the average holding current at the baseline.

\section{Quantification and statistical analysis}

Statistically significant outliers were calculated and excluded, using the Grubb's Test. Data were analyzed either using a one- or two-way ANOVA (repeated measures), or one-way ANCOVA where indicated, with multiple comparisons and post-hoc Bonferroni's test, as indicated in figure legends. For electrophysiological recordings, paired $t$ tests were used to compare neuronal responses to NMDA before and after APV. Data analysis was not blinded. For single-cell RNAseq and cell-type specific ATACseq results, data was compared using Wilcoxon rank-sum tests. Differences in means were considered statistically significant at $p<0.05$. Significance levels are as follows; $* p<0.05 ; * * p$ $<0.01 ; * * * p<0.001 ; * * * *<<0.0001, \mathrm{~ns}-$ not significant. All data analyses were performed using the Graphpad Prism 6.0 software and/or IBM SPSS 23.0 Software and using custom analysis scripts written in $\mathrm{R}$.

Acknowledgements The authors would like to acknowledge Beverly Koller for donation of the pXena targeting construct, and Marc Caron, Bob Lefkowitz, Michael Didriksen, Jean-Martin Beaulieu, and Stephane Angers for helpful discussion. The authors would like to acknowledge Chinmaya Sadangi for preliminary work on RNAscope microscopy. Computations were performed on the CAMH Specialised Computing Cluster. The SCC is funded by: The Canada Foundation for Innovation, Research Hospital Fund.

Funding This work was supported by CIHR funding to AJR (MOP119298), EKL (MOP89825 and Canada Research Chair in Developmental Cortical Physiology) and AS (MOP206649) and by NIMH to REM and AJF (MH107916 and L.I.F.E.). The work was also supported by graduate scholarships from CIHR and OGS to CAM, OGS to MAB and a postdoctoral fellowship from Stiftelsen Olle Engkvist Byggmästare to EMJ.

\section{Compliance with ethical standards}

Conflict of interest The authors declare that they have no conflict of interest.

Publisher's note Springer Nature remains neutral with regard to jurisdictional claims in published maps and institutional affiliations.

Open Access This article is licensed under a Creative Commons Attribution 4.0 International License, which permits use, sharing, adaptation, distribution and reproduction in any medium or format, as long as you give appropriate credit to the original author(s) and the source, provide a link to the Creative Commons license, and indicate if changes were made. The images or other third party material in this article are included in the article's Creative Commons license, unless indicated otherwise in a credit line to the material. If material is not included in the article's Creative Commons license and your intended use is not permitted by statutory regulation or exceeds the permitted use, you will need to obtain permission directly from the copyright holder. To view a copy of this license, visit http://creativecommons.org/licenses/by/4.0/.

\section{References}

1. Maulik PK, Mascarenhas MN, Mathers CD, Dua T, Saxena S. Prevalence of intellectual disability: a meta-analysis of population-based studies. Res Dev Disabil. 2011;32:419-36.

2. Fombonne E. Epidemiology of pervasive developmental disorders. Pediatr Res. 2009;65:591-8. 
3. Mohammed S, Scott R, Vogt J, Al-Turki S, Cross G, Smithson S, et al. Large-scale discovery of novel genetic causes of developmental disorders. Nature. 2014;519:223-8.

4. XiangWei W, Jiang Y, Yuan H. De novo mutations and rare variants occurring in NMDA receptors. Curr Opin Physiol. 2018;2:27-35.

5. Guy J, Gan J, Selfridge J, Cobb S, Bird A. Reversal of neurological defects in a mouse model of Rett syndrome. Science. 2007;315:1143-7.

6. Mei Y, Monteiro P, Zhou Y, Kim J-AA, Gao X, Fu Z, et al. Adult restoration of Shank3 expression rescues selective autistic-like phenotypes. Nature. 2016;530:481-4.

7. Li Y, Erzurumlu RS, Chen C, Jhaveri S, Tonegawa S. Whiskerrelated neuronal patterns fail to develop in the trigeminal brainstem nuclei of NMDAR1 knockout mice. Cell. 1994;76:427-37.

8. Suzuki A, Lo F-S, Zhao S, Itohara S, Hayashi Y, Arakawa H, et al. Thalamic NMDA receptor function is necessary for patterning of the thalamocortical somatosensory map and for sensorimotor behaviors. J Neurosci. 2014;34:12001-14.

9. Iwasato T, Datwani A, Wolf AM, Nishiyama H, Taguchi Y, Tonegawa $\mathrm{S}$, et al. Cortex-restricted disruption of NMDAR1 impairs neuronal patterns in the barrel cortex. Nature. 2000;406:726-31.

10. Gu X, Zhou L, Lu W. An NMDA receptor-dependent mechanism underlies inhibitory synapse development. Cell Rep. 2016;14:471-8.

11. Zhang Z-w, Peterson M, Liu H. Essential role of postsynaptic NMDA receptors in developmental refinement of excitatory synapses. Proc Natl Acad Sci. 2013;110:1095-100.

12. Espinosa JS, Wheeler DG, Tsien RW, Luo L. Uncoupling dendrite growth and patterning: single-cell knockout analysis of NMDA receptor 2B. Neuron. 2009;62:205-17.

13. Lemke JR, Geider K, Helbig KL, Heyne HO, Schütz H, Hentschel J, et al. Delineating the GRIN1 phenotypic spectrum: a distinct genetic NMDA receptor encephalopathy. Neurology. 2016;86:2171-8.

14. Forrest D, Yuzaki M, Soares HD, Ng L, Luk DC, Sheng M, et al. Targeted disruption of NMDA receptor 1 gene abolishes NMDA response and results in neonatal death. Neuron. 1994;13:325-38.

15. Mohn AR, Gainetdinov RR, Caron MG, Koller BH. Mice with reduced NMDA receptor expression display behaviors related to schizophrenia. Cell. 1999;98:427-36.

16. Tasic B, Yao Z, Graybuck LT, Smith KA, Nguyen TN, Bertagnolli D, et al. Shared and distinct transcriptomic cell types across neocortical areas. Nature. 2018;563:72-8.

17. Long MA, Rossi FMV. Silencing inhibits cre-mediated recombination of the Z/AP and Z/EG reporters in adult cells. PLoS ONE. 2009;4:1-8.

18. Gray LT, Yao Z, Nguyen TN, Kim TK, Zeng H, Tasic B. Layerspecific chromatin accessibility landscapes reveal regulatory networks in adult mouse visual cortex. Elife. 2017;6:e21883.

19. Rompala GR, Zsiros V, Zhang S, Kolata SM, Nakazawa K. Contribution of NMDA receptor hypofunction in prefrontal and cortical excitatory neurons to schizophrenia-like phenotypes. PLoS ONE. 2013;8:e61278.

20. Belforte JE, Zsiros V, Sklar ER, Jiang Z, Yu G, Li Y, et al. Postnatal NMDA receptor ablation in corticolimbic interneurons confers schizophrenia-like phenotypes. Nat Neurosci. 2010;13:76-83.

21. Finlay JM, Dunham GA, Isherwood AM, Newton CJ, Nguyen TV, Reppar PC, et al. Effects of prefrontal cortex and hippocampal NMDA NR1-subunit deletion on complex cognitive and social behaviors. Brain Res. 2015;1600:70-83.

22. Yamaguchi S, Hale LA, D'Esposito M, Knight RT. Rapid prefrontal-hippocampal habituation to novel events. J Neurosci. 2004;24:5356-63.
23. Ranganath C, Rainer G. Cognitive neuroscience: neural mechanisms for detecting and remembering novel events. Nat Rev Neurosci. 2003;4:193-202.

24. Li L, Du Y, Li N, Wu X, Wu Y. Top-down modulation of prepulse inhibition of the startle reflex in humans and rats. Neurosci Biobehav Rev. 2009;33:1157-67.

25. Duncan GE, Moy SS, Perez A, Eddy DM, Zinzow WM, Lieberman JA, et al. Deficits in sensorimotor gating and tests of social behavior in a genetic model of reduced NMDA receptor function. Behav Brain Res. 2004;153:507-19.

26. Ben Abdallah NM-B, Fuss J, Trusel M, Galsworthy MJ, Bobsin $\mathrm{K}$, Colacicco G, et al. The puzzle box as a simple and efficient behavioral test for exploring impairments of general cognition and executive functions in mouse models of schizophrenia. Exp Neurol. 2011;227:42-52.

27. Ventura A, Kirsch DG, McLaughlin ME, Tuveson DA, Grimm J, Lintault $\mathrm{L}$, et al. Restoration of p53 function leads to tumour regression in vivo. Nature. 2007;445:661-5.

28. Vogt MAA, Chourbaji S, Brandwein C, Dormann C, Sprengel R, Gass P. Suitability of tamoxifen-induced mutagenesis for behavioral phenotyping. Exp Neurol. 2008;211:25-33.

29. Intson K, van Eede MC, Islam R, Milenkovic M, Yan Y, Salahpour A, et al. Progressive neuroanatomical changes caused by Grin1 loss-of-function mutation. Neurobiol Dis. 2019;132:104527.

30. Chen Y, Milenkovic M, Horsfall W, Salahpour A, Soderling SH, Ramsey AJ. Restoring striatal WAVE-1 improves maze exploration performance of GluN1 knockdown mice. PLoS ONE. 2018;13:e199341.

31. Ramsey AJ, Milenkovic M, Oliveira AF, Escobedo-Lozoya Y, Seshadri S, Salahpour A, et al. Impaired NMDA receptor transmission alters striatal synapses and DISC1 protein in an agedependent manner. Proc Natl Acad Sci USA. 2011;108:5795-800.

32. Millan MJ, Agid Y, Brüne M, Bullmore ET, Carter CS, Clayton NS, et al. Cognitive dysfunction in psychiatric disorders: Characteristics, causes and the quest for improved therapy. Nat Rev Drug Discov. 2012;11:141-68.

33. Tarabeux J, Kebir O, Gauthier J, Hamdan FF, Xiong L, Piton A, et al. Rare mutations in N-methyl-D-aspartate glutamate receptors in autism spectrum disorders and schizophrenia. Transl Psychiatry. 2011;1:e55.

34. Van Duyne G. D. Cre recombinase. Microbiol. Spectr. 3: MDNA3-0014-2014. https://doi.org/10.1128/microbiolspec. MDNA3-0014-2014. 2015;119-38.

35. Speed HE, Kouser M, Xuan Z, Liu S, Duong A, Powell CM. Apparent genetic rescue of adult shank3 exon 21 insertion mutation mice tempered by appropriate control experiments [published correction appears in eNeuro. 2020 Mar 9;7 (2):]. eNeuro. 2019;6(5):ENEURO.0317-19.2019. Published 2019 Sep 27. https://doi.org/10.1523/ENEURO.0317-19.2019.

36. López-Rivera JA, Pérez-Palma E, Symonds J, Lindy AS, McKnight DA, Leu C, et al. A catalogue of new incidence estimates of monogenic neurodevelopmental disorders caused by de novo variants. Brain. 2020;143:1099-1105. https://doi.org/10. 1093/brain/awaa051.

37. Lemke J. Predicting incidences of neurodevelopmental disorders. Brain. 2020:1046-8. https://www.ncbi.nlm.nih.gov/pubmed/? term $=32318731$. Accessed 4 May 2020.

38. Hamdan FF, Gauthier J, Araki Y, Lin DT, Yoshizawa Y, Higashi $\mathrm{K}$, et al. Excess of de novo deleterious mutations in genes associated with glutamatergic systems in nonsyndromic intellectual disability. Am J Hum Genet. 2011;88:306-16.

39. Yu Y, Lin Y, Takasaki Y, Wang C, Kimura H, Xing J, et al. Rare loss of function mutations in $\mathrm{N}$-methyl-d-aspartate glutamate receptors and their contributions to schizophrenia susceptibility. Transl Psychiatry. 2018;8:12. 
40. Madisen L, Zwingman TA, Sunkin SM, Oh SW, Zariwala HA, Gu $\mathrm{H}$, et al. A robust and high-throughput Cre reporting and characterization system for the whole mouse brain. Nat Neurosci. 2010;13:133-40.

41. Silva AJ, Simpson EM, Takahashi JS, Lipp HP, Nakanishi S, Wehner JM, et al. Mutant mice and neuroscience: recommendations concerning genetic background. Neuron. 1997;19:755-9.

42. Islam R, Trépanier M-O, Milenkovic M, Horsfall W, Salahpour A, Bazinet RP, et al. Vulnerability to omega- 3 deprivation in a mouse model of NMDA receptor. Npj Schizophr. 2017;3:12.

43. Mielnik CA, Horsfall W, Ramsey AJ. Diazepam improves aspects of social behaviour and neuron activation in NMDA receptordeficient mice. Genes Brain Behav. 2014;13:592-602.

44. Milenkovic M, Mielnik CA, Ramsey AJ. NMDA receptordeficient mice display sexual dimorphism in the onset and severity of behavioural abnormalities. Genes Brain Behav. 2014;13:850-62.

45. Moy SS, Nadler JJ, Young NB, Perez A, Holloway LP, Barbaro $\mathrm{RP}$, et al. Mouse behavioral tasks relevant to autism: Phenotypes of 10 inbred strains. Behav Brain Res. 2007;176:4-20.

46. DeBlasi A, O'Reilly K, Motulsky HJ. Calculating receptor number from binding experiments using same compound as radioligand and competitor. Trends Pharmacol Sci. 1989;10: 227-9.

47. Sullivan CR, Mielnik CA, O’Donovan SM, Funk AJ, Bentea E, DePasquale EA, et al. Connectivity analyses of bioenergetic changes in schizophrenia: identification of novel treatments. Mol Neurobiol. 2018;56:4492-517.

48. Paxinos G, Franklin KBJ. The mouse brain in stereotaxic coordinates. 2nd edition, Academic Press, San Diego. 2001. 